\title{
Damage control surgery: a new "way of thinking" in the treatment of the critically injuried
}

\author{
Antonio Martino ${ }^{1}$, Ciro De Martino ${ }^{2 *}$, Gautam Maharajan', Marco Evangelista', Rosa Maria Giamattei', \\ Anna Pisapia ${ }^{2}$ \\ From XXIII Annual Meeting of the Italian Society of Geriatric Surgery \\ Lecce, Italy. 2-4 December 2010
}

\section{Background}

Damage control is well established as a potentially lifesaving procedure in a few selected critically injured patients. In these patients the "lethal triad" of hypothermia, acidosis, and coagulopathy is presented as a vicious cycle that often cannot be interrupted and which marks the limit of the patient's ability to cope with the physiological consequences of injury.

The principles of damage control have led to improved survival and to the stopping of bleeding until the physiologic derangement has been restored and the patient could undergo a prolonged operation for definitive repair.

\section{Methods}

There are five critical decision-making stages of damage control: I, patient selection and decision to perform damage control; II, operation and intraoperative reassessment of laparotomy; III, resuscitation in the intensive care unit; IV, definitive procedures after returning to the operating room; and $\mathrm{V}$, abdominal wall reconstruction.

\section{Results}

Although morbidity remains high, it is acceptable if it comes in exchange for improved survival. Damage control surgery offers a simple effective alternative to the traditional surgical management of complex or multiple injuries in critically injured patients. Phases I and II can be done at a rural hospital before transfer to a major trauma centre for definitive repair.

\section{Conclusions}

There is a complex interplay between primary injury, particularly major abdominal injury in the multi-system trauma patient, and secondary injury, which relates to patient physiology, decision making and surgical technique. Analysis of outcomes is further confounded by the variety of surgical techniques used. The challenge is to match the correct operation, for a critically injured patient, with the patient's physiology. Excellence in general surgery does not equate with excellence in trauma surgery, and a clear understanding of damage control is essential.

\section{Author details}

${ }^{1}$ Casa di Cura "A. Grimaldi" di San Giorgio a Cremano (NA). Dipartimento di Chirurgia, Italy. ${ }^{2}$ Università degli Studi di Napoli "Federico II". U.O.C. di Chirurgia Generale, Italy.

Published: 24 August 2011

\section{References}

1. Germanos S, Gourgiotis S, Villias C, Bertucci M, Dimopoulos N, Salemis N: Damage control surgery in the abdomen: an approach for the management of severe injuried patients. Int J Surg 2008, 6(3):246-52.

2. Sugrue M, D'Amours SK, Joshipura M: Damage control surgery and the abdomen. Injury 2004, 35(7):642-8.

3. Bashir MM, Abu-Zidan FM: Damage control surgery for abdominal trauma. Eur J Surg 2003, 588(Suppl.):8-13.

\section{doi:10.1186/1471-2318-11-S1-A31}

Cite this article as: Martino et al:: Damage control surgery: a new "way of thinking" in the treatment of the critically injuried. BMC Geriatrics 2011 11(Suppl 1):A31.

\footnotetext{
* Correspondence: ciro.de@tiscali.it

¿Università degli Studi di Napoli "Federico II". U.O.C. di Chirurgia Generale, Italy

Full list of author information is available at the end of the article
} 